\title{
An Analysis on Minimization of Product Error (Poka-Yoke) and Excess Work in Progress (TPM \& OEE) in Textile Industry
}

\author{
J. Yashini* \\ Student, KCT Business School, Kumaraguru College of Technology, Coimbatore, India \\ *Corresponding author: yashni.j@gmail.com
}

\begin{abstract}
The rapid change in textile styles, deviation of order quantities and increasing quality levels at the lowest possible cutrate, demand the textile manufacturing industry to be focused on more effective and efficient manufacturing processes for survival in an immensely competitive market. To increase the productivity of the textile industries we need to reduce the manufacturing defects and time to manufacture the product. Lean is the tool to reduce the wastage in all process of textile manufacturing, reducing cost and value added to the product. This paper proposes the lean tool like POKA-YOKE, DPMO, cause and effect diagram \&OEE to reduce the overall product error and work-in-progress. Analysis covers the area of c poka - yoke which is any effort to eliminate human errors in the system. In short, Error=mistakes = defects. Therefore, the removal and control of errors eliminates defects. And specific section of sewing line was OEE is applied to investigate the existing condition of machine and provide recommendation to improve present condition in Classic Polo Textile industry to reduce work-in-progress.
\end{abstract}

Keywords: Cause and effect diagram, Defects, DPMO, POKAYOKE, Rework, TPM \& OEE.

\section{Introduction}

This study is carried out in classic polo private limited, Tirupur. This company comprises all departments like cutting department, sewing department, ironing and packing department all under one roof. The scope of the study is to reduce the product error and work-in-progress by applying lean manufacturing tool like POKA-YOKE, TPM \& OEE to identify and eliminate product error, work-in-progress, the improvement of quality, and production time and cost reduction to provide a high-quality product without error to their customer by satisfying their requirements.

\section{A. Need for the study}

The major problem in classic polo is to reduce the product error and on time delivery. According to AQL chart the buyer may reject the entire product if one defect is in exceed than provided in the AQL limit and if there is time delay, they have sent the products through air instead of shipping which results in loss. Lean tool techniques are adopted to reduce this error and improve efficiency.
B. Objectives of the study

1) Primary objective

- To Study about the minimization of the product error (Poka- yoke) and elimination of building excess Work in Progress (TPM\&OEE) in Production Line.

2) Secondary objective

- To know about Workload balancing to improve Output (cross functional team).

- To Observe and analyze the various issue faced by textile industry.

- $\quad$ To analyze the quality of the product (AQL).

\section{Research Methodology}

Descriptive research is defined as a research method that describes the characteristics of the population or phenomenon that is being studied. This methodology focuses more on the "what" of the research subject rather than the "why" of the research subject.

- To identify areas for further research

- To help in planning resource allocation

- To provide informal information about a condition.

\section{A. Sources of data}

The data will be collected from officials of the industry through interaction which are required for the completion of the project.

\section{B. Instruments of data collection}

The data are collected directly from the officials and employees by observation, questionnaires and interviews.

\section{Primary data collection}

The primary data will be collected from officials and employees through interviews and questionnaires.

\section{Secondary data collection}

The secondary data will be collected from the journals and literatures. 
Volume-3, Issue-9, September-2020

\section{IJRESM journals.resaim.com/ijresm | ISSN (Online): 2581-5792 | RESAIM Publishing}

\section{Analysis and Interpretation}

A. Regular average monthly production data

Table 1

Regular average monthly production

\begin{tabular}{|l|l|l|}
\hline Confirmed piece & Rework piece & Rejected piece \\
\hline $1,30,000$ & $6500(4 \%-5 \%)$ & $2600(1 \%-2 \%)$ \\
\hline
\end{tabular}

B. Process in sewing section

Table 2

Process in sewing section

\begin{tabular}{|c|l|c|}
\hline S. no. & \multicolumn{1}{|c|}{ Operating Functions } & No. of operators \\
\hline 1. & Yoke surging & 1 \\
\hline 2. & Yoke label & 2 \\
\hline 3. & Bottom and Sleeve hemming & 1 \\
\hline 4. & Placket attaching & 3,4 \\
\hline 5. & Pocket stitching & 2,3 \\
\hline 6. & Shoulder stitching & 1 \\
\hline 7. & Collar join & 1 \\
\hline 8. & Sleeve join & 2 \\
\hline 9. & Side seam & 2 \\
\hline 10. & Slit stich & 1 \\
\hline 11. & Bottom labelling & 1 \\
\hline 12. & Peek & 1 \\
\hline 13. & Bar-tack & 1 \\
\hline 14. & Kaja, button stich & 1 \\
\hline 15. & Quality check & 2 \\
\hline
\end{tabular}

\section{P-Chart}

The quality level of the dress is based on Acceptance Quality Limit (AQL) chart. There are different limits like 1.5, 2.5, 4, 6.5. The AQL followed by most the buyers are 2.5. all the companies reject to accept the AQL 1.5 which us very difficult to manufacture. In 2.5 standard for 1000 pieces the checking quantity is 80 pieces.

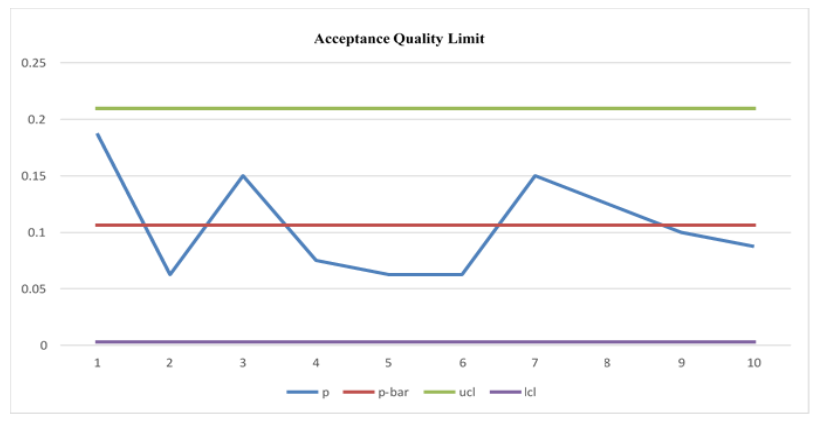

Fig. 1. Acceptance Quality Limit (AQL) chart

\section{Measure of DPMO}

The term DPMO or defects per million opportunities is one of the important six sigma metrics. This value allows you to determine how effective your process is. It also allows for a comparison between processes. Similar to PPM or parts per million, DPMO provides a more in depth look at process effectiveness.

In this the percentage of defect, capability study existing DPMO of selected product was calculated.

Number of checked pieces $=130000$

Number of confirming pieces $=123500$

Number of non-confirming pieces $=6500$
$\mathrm{DPMO}=($ Number of non-confirming items/ Number of checked items) $* 1000000$

DPMO $=50,000$

Proportion of defectives $=(\mathrm{DPMO} / 1000000)$

Proportion of defectives $=0.05$

Proportion of confirming unit $=1-0.05=0.95$

Percentage of confirming unit $=95 \%$

Percentage of defect $=5 \%$

Percentage of rework in last month is $5 \%$

\section{E. Cost of Rework}

In garment industry reworking a piece of garment takes 3 times more than making on a first-time good piece. Having 6500 piece of rework is equivalent to stitching $6500 * 3=19500$ pieces at specific operation. So, the average time of operation for stitching a particular part is around 50 sec.so total time on rework is,

$(\mathrm{SAM} *$ Total number of rework $) / 50=(60 * 6500) / 50=7800$ minute. Average garment value for one operator for one minute is $0.62 / \mathrm{min}=7800 * 0.62=4836$ Rupees.

Table 3

Cost of rework for a month

\begin{tabular}{|l|l|l|l|l|l|}
\hline Rework & SAM & $\begin{array}{c}\text { No of } \\
\text { Rework*3 }\end{array}$ & $\begin{array}{c}\text { Time on } \\
\text { Rework } \\
\text { (min) }\end{array}$ & $\begin{array}{c}\text { Garment } \\
\text { Min value }\end{array}$ & $\begin{array}{c}\text { Operator } \\
\text { Cost for } \\
\text { rework }\end{array}$ \\
\hline Shoulder & 33 & 1572 & 864.6 & 0.62 & 524.89 \\
\hline Neck rib & 5 & 1026 & 85.5 & 0.62 & 53.12 \\
\hline $\begin{array}{l}\text { Neck } \\
\text { seam }\end{array}$ & 38 & 2055 & 1301.5 & 0.62 & 806.93 \\
\hline $\begin{array}{l}\text { Paste } \\
\text { label }\end{array}$ & 13 & 1239 & 268.45 & 0.62 & 166.43 \\
\hline $\begin{array}{l}\text { Collar } \\
\text { close }\end{array}$ & 42 & 1794 & 1255.8 & 0.62 & 778.59 \\
\hline $\begin{array}{l}\text { Hem } \\
\text { sleeve }\end{array}$ & 42 & 2379 & 1339.8 & 0.62 & 830.67 \\
\hline $\begin{array}{l}\text { Sleeve } \\
\text { stitch }\end{array}$ & 58 & 1914 & 1850.2 & 0.62 & 1147.12 \\
\hline Side seam & 56 & 2505 & 2338 & 0.62 & 1449.56 \\
\hline Peak & 21 & 1641 & 574.3 & 0.62 & 356.06 \\
\hline Bar-tack & 20 & 759 & 253 & 0.62 & 156.86 \\
\hline Hemming & 42 & 2316 & 1612.2 & 0.62 & 988.5 \\
\hline Total & & & & & 7258.73 \\
\hline
\end{tabular}

The total amount wasted on rework for a month on rework is 7258.73 .

\section{F. Implementation of POKA-YOKE to reduce this product} error and rework

Its purpose is to eliminate product defects by preventing, correcting, or drawing attention to human errors as they occur Poka-Yoke helps in developing a process or a system that enables quality to be built during the manufacturing process, while also authorizing operators to stop the line in case the product does not conform to the specifications.

Based on working methodologies, Poka-Yoke tool can be classified into following two types:

- Prevention based

- Detection based 


\section{G. Prevention-based Poka-Yoke}

Prevention-based mechanisms sense an abnormality that is about to happen, and then signals the occurrence or halts the process, depending on the severity, frequency or downstream consequences. There are two approaches for prevention-based Poka-yoke.
- Control Method
- Warning Method

\section{H. Detection-based Poka-Yoke}

Shop floor experiences have shown that detection- based Poka-Yoke can be implemented in three ways in apparel industry:

- Fixed Value Method

- Contact Method

- Motion step method

Following is the detail discussion of processes, manufacturing and the use of poka-yoke devices. If spinning, weaving and bleaching departments are automated, so there is less human involvement and less human error.

\section{1) Spinning}

The process starts with making thread from the cotton. cotton comes in as a raw material in the textile manufacturing. It takes processes to separate the dust from the cotton. The only thing to take care of is that the sliver thread does not break.

2) Weaving

Making fabric from the thread. Problem which usually occur are the needle breakage in looms, thread breakage, oil leakage, warp and weft defect and contamination occurs this is mainly due to the Operator negligence Hence this defect occurs, it is rectified by the worker. To further avoid the defects, operators are briefed. Operators full attention is needed to supervise the work of the machine, to ensure that machine is working properly.

3) Contamination in weaving

Contamination in weaving process cannot be removed except winding. In winding contamination is not visible my naked eye but it can be detected by optical clearing sensors and will be removed along with some yarn as waste material.it is beneficial to remove contamination before going to further process.

\section{4) Stitching \& Packing}

Inline inspection is held Quality auditors check the stitching 3-4 times a day. They may include 1-inch auditing system to check all double stitch, skip stitch etc.

a) Stitch quality monitoring system

- They may install this for top AQL demanded products.

- Now-a-days there are automated dobby, automatic pick repair, automated wrap breakage locator to reduce human error.

\section{5) Embroidery}

Companies using 1st level poka-yoke were thread breakage is detected by Andon. Andon is a red-light bulb which lightens whenever thread breaks. As it lights machine stops at spot indicating about the particular section where the problems have occurred.

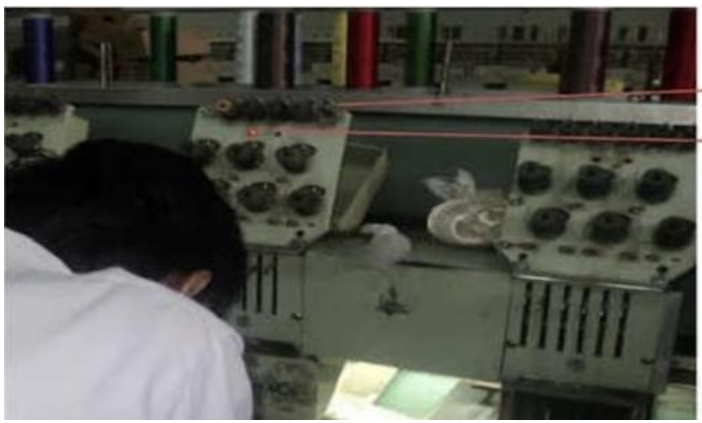

Fig. 2. Embroidery

The machine instead of requiring an operator to stand over them constantly observing them to ensure nothing went were instil with "intelligence" so that they stopped when something went wrong. By using this the operator may watch several machines than watching one which making it cost effective for company. It may also be an array of lights found on a single board that signals a team leader where abnormality found. Below diagram shows an Andon light turning red when defect is detected.

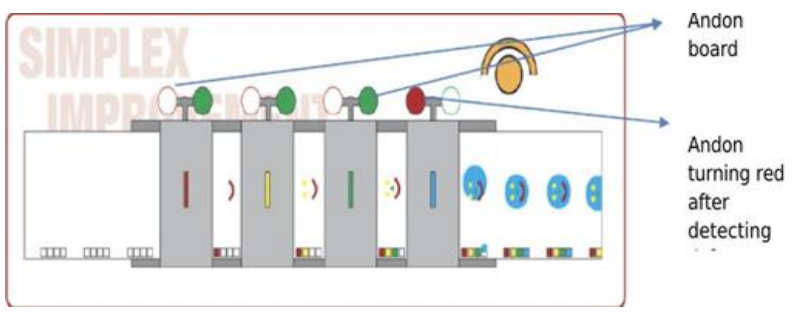

Fig. 3. Andon light

\section{Metal detector}

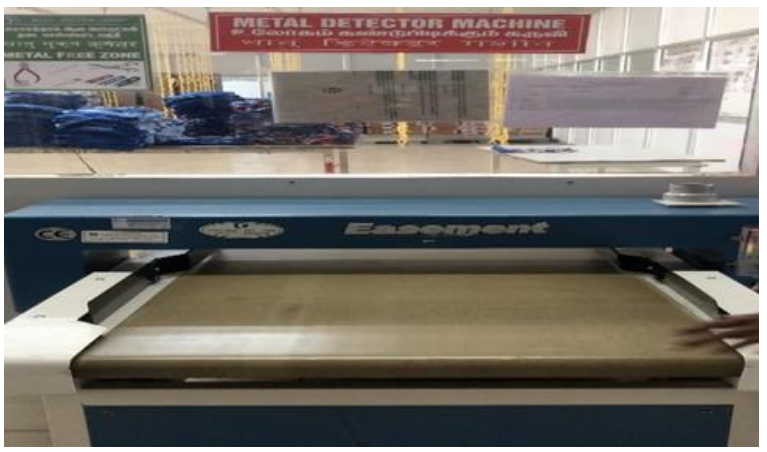

Fig. 4. Metal detector

Metal detector is used to find out any broken needles or any metals in the product in final checking to reduce the critical problems.

\section{J. Cause and effect diagram}

The cause and effect diagram for product error were drawn to identify the root cause of the problem and here the product error like skip stitch, stain, broken stitch is due to the lack of 
skill, Long time needle usage, improper machine usage and several factors were analysed. The critical cause of each acute defect of product was found through this cause and effect diagram.

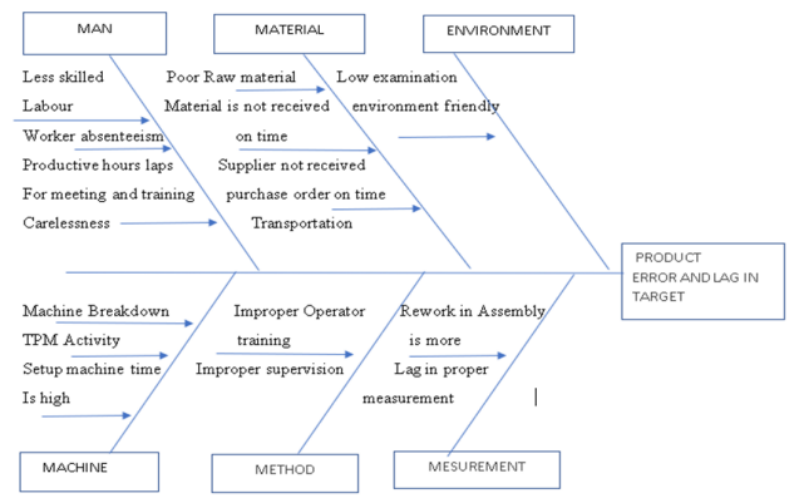

Fig. 5. Cause and effect diagram

K. Solution for the cause

To make sure sewing machine is properly maintained, Regular change in needle, Corrective setting of the machine to the cloth, observe sewing operation for better material handling and switching person depending on their speed and capability. There may be a piece rate instead of swift base to reduce time and product error.

Table 4

\begin{tabular}{|l|l|}
\hline \multicolumn{1}{|c|}{ Instructions to prevent error } \\
\hline Wrinkle & \multicolumn{1}{c|}{ Solution } \\
& $\begin{array}{l}\text { 1.Parts should be joined carefully } \\
\text { 2. Heating of Fabric from specific distance can be } \\
\text { effective }\end{array}$ \\
\hline $\begin{array}{l}\text { Wrong puller } \\
\text { insertion }\end{array}$ & $\begin{array}{l}\text { 1. Advice operator to put more attention while } \\
\text { inserting puller. } \\
\text { 2. Alter operator for reducing monotonous. }\end{array}$ \\
\hline Broken, skip stitch & $\begin{array}{l}\text { 1. Tension of bobbing cage and needle thread should } \\
\text { be adjusted. } \\
\text { 2. Advice to trim thread attentively. }\end{array}$ \\
\hline Uneven stitch & $\begin{array}{l}\text { A little more training and attention can solve this } \\
\text { problem partially. }\end{array}$ \\
\hline
\end{tabular}

L. Total Productive Maintenance

TPM (Total Productive Maintenance) is a holistic approach to equipment maintenance that strives to achieve perfect production:

- No Breakdowns

- No Small Stops or Slow Running

- No Defects

In addition, it values a safe working environment:

- No Accidents

The objectives behind to adopt TPM

- Evade wastage in a rapidly changing economic environment.

- Manufacturing goods without dipping product quality.

- Attain Zero Defects, Zero Breakdown and Zero accidents in all functional areas of the organization.

\section{1) Equipment effectiveness before application of total} productive maintenance

In the manufacturing process there are defective product due to inefficient maintenance of the machine and machine breakdown which also leads to time delay. In order to satisfy customer, the product must be defect free. Defect free products requires machine without trouble. Before application of TPM there are breakdown of machine led to product error and poor customer satisfaction.

2) Equipment effectiveness after application of total productive maintenance

After implementation of TPM, the workers were educated at every level of production process about TPM, Labels and Signs in machine used to identify the machine that need special attention, remained operator to perform daily maintenance which improved their productivity and on time delivery due to non-breakdown of machine.

\section{Overall Equipment Effectiveness (OEE)}

OEE is the framework for measuring the efficiency and effectiveness of a process, by breaking it down into three constituent components (Availability, Performance and Quality product rate). It helps to measure a problem so that easily can fix it and provides a standardized method of benchmarking progress. OEE identifies the percentage of planned production time that is truly productive.

Overall machine or equipment efficiency is the how to performs machine versus spec. In practically,

$\mathrm{OEE}=$ Availability $(\mathrm{A}) *$ Performance $(\mathrm{P}) * \mathrm{Quality}(\mathrm{Q})$

\section{1) Availability}

Availability takes into account all events that stop planned production long enough where it makes sense to track a reason for being down (typically several minutes).

Availability $=$ Run Time / Planned Production Time

Run Time $=$ Planned Production Time - Stop Time

\section{2) Performance}

Performance takes into account anything that causes the manufacturing process to run at less than the maximum possible speed when it is running (including both Slow Cycles and Small Stops).

Performance $=$ Net Run Time $/$ Run Time

Net Run Time $=$ Ideal cycle time* Total count

\section{3) Quality}

Quality takes into account manufactured parts that do not meet quality standards, including parts that need rework. Remember, OEE Quality is similar to First Pass Yield, in that it defines Good Parts as parts that successfully pass through the manufacturing process the first time without needing any rework.

Quality = Good Count $/$ Total Count 
Volume-3, Issue-9, September-2020

\section{IJRESM journals.resaim.com/ijresm | ISSN (Online): 2581-5792 | RESAIM Publishing}

4) Overall equipment effectiveness analysis

Table 5

Overall equipment effectiveness

\begin{tabular}{|c|c|c|c|c|c|}
\hline $\begin{array}{c}\text { S. } \\
\text { no. }\end{array}$ & Machine & $\begin{array}{c}\text { Down } \\
\text { time } \\
\text { time }\end{array}$ & $\begin{array}{c}\text { Rycle } \\
\text { time }\end{array}$ & $\begin{array}{c}\text { Reject } \\
\text { per day }\end{array}$ \\
\hline 1. & $\begin{array}{c}\text { Over lock } \\
\text { (shoulder join) }\end{array}$ & 47 & 413 & 0.24 & 12 \\
\hline 2. & $\begin{array}{c}\text { Lock stich } \\
\text { (neck rib tuck) }\end{array}$ & 38 & 422 & 0.26 & 5 \\
\hline 3. & $\begin{array}{c}\text { Overlock } \\
\text { (neck join) }\end{array}$ & 48 & 412 & 0.29 & 9 \\
\hline 4. & $\begin{array}{c}\text { Flat lock } \\
\text { (neck top) }\end{array}$ & 46 & 414 & 0.28 & 5 \\
\hline 5. & $\begin{array}{c}\text { Lock stitch } \\
\text { (back neck) }\end{array}$ & 35 & 425 & 0.45 & 10 \\
\hline 6. & $\begin{array}{c}\text { Flat lock } \\
\text { (sleeve hem) }\end{array}$ & 43 & 417 & 0.50 & 13 \\
\hline 7. & $\begin{array}{c}\text { Overlock } \\
\text { (sleeve hem) }\end{array}$ & 32 & 428 & 0.48 & 6 \\
\hline 8. & $\begin{array}{c}\text { Flat lock (side } \\
\text { seam) }\end{array}$ & 52 & 408 & 0.68 & 10 \\
\hline 9. & Lock stitch(tuck) & 43 & 417 & 0.23 & 12 \\
\hline 10. & $\begin{array}{c}\text { Flat lock } \\
\text { (body hem) }\end{array}$ & 46 & 414 & 0.28 & 10 \\
\hline 11. & Iron machine & 25 & 435 & 0.55 & 3 \\
\hline 12. & Metal detector & 23 & 437 & 0.08 & 0 \\
\hline
\end{tabular}

\section{5) OEE calculation}

The OEE of the selected production line is calculated. Here, shift time is 9 hours so $540 \mathrm{~min}$, Scheduled break time is 60 min, planned production time $=540 \mathrm{~min}$, Non-scheduled break time is $20 \mathrm{~min}$. Here the down time includes equipment failure, idling and minor stoppage, speed loss, defects (scarp and rework), start-up etc. The following table represents OEE condition of the selected production line of the selected floor.

The overall OEE level of the studied production line is 75.2 percent.

\section{N. Findings}

- It has been found that the average production per day is 18000 pieces.

- By applying DPMO rework rate was found to be 5\% and rework cost was 7258.72 per month.

- The overall OEE level of the studied production line is 75.2 percent.

- Time consumption after following zigzag layout and quality check in sewing section.

- Lack of training about machine pressure adjustment and proper machine service.

- Time delay in case of machine breakdown by shift workers.

O. Suggestions

- OEE can be increased by scheduled maintenance of machine before breakdown.

- Tension of bobbing cage and needle thread should be adjusted before every operation.

- Wrap and Weft errors are due to the machine which leaves any thread during weaving. There must be a use of automated stop units, which stops as it leaves any thread.

- As company has to prepare the order earlier due to urgency of the shipment, shade variation occurs. To avoid shade variation put a scale on the dryer let know the variation occur. When acceptable level of dryness is achieved during dyeing the process can be stopped.

- Color sensor are helpful in early detection of contamination which alarms the operator when error occurred.

- Automated machine can be installed for high quality AQL demand. Nowadays there are automated dobby, automatic pick repair, automated wrap breakage locator to reduce human error.

- Heating of Fabric from specific distance can be effective by using laser light.

- Maximum piece rate wages can be obtained to reduce voluntary time lag.

\section{Conclusion}

The most difficult thing in manufacturing is producing a right quality product for all the right time and work toward manufacturing a best quality product for good customer satisfaction, still it is important to work on improving product quality to satisfy customers, to control production cost and to save energy. From the study it is analyzed that the overall equipment effectiveness level of the taken production line is Table 6

Overall equipment effectiveness percentage

\begin{tabular}{|l|l|l|l|l|l|l|}
\hline Machine name & Total Production & Rejected Production & Availability \% & Perform \% & Quality \% & OEE \% \\
\hline Overlock & 1430 & 12 & 86.04 & 83.09 & 99.16 & 71.05 \\
\hline Lockstitch & 1390 & 5 & 87.91 & 85.63 & 99.64 & 75.00 \\
\hline Overlock & 1212 & 9 & 85.33 & 85.31 & 99.25 & 72.24 \\
\hline Flatlock & 1237 & 5 & 86.25 & 83.64 & 99.59 & 71.84 \\
\hline Lockstitch & 810 & 10 & 88.54 & 85.76 & 98.76 & 74.99 \\
\hline Flatlock & 736 & 13 & 86.87 & 87.76 & 98.27 & 74.91 \\
\hline Overlock & 760 & 6 & 89.16 & 85.23 & 99.21 & 75.39 \\
\hline Flatlock & 495 & 10 & 85 & 82.5 & 97.97 & 68.70 \\
\hline Lockstitch & 1567 & 12 & 86.87 & 86.42 & 99.23 & 74.49 \\
\hline Flatlock & 1230 & 10 & 86.25 & 83.18 & 99.18 & 71.15 \\
\hline Ironing & 740 & 3 & 90.62 & 92.28 & 99.61 & 83.29 \\
\hline Detector & 4780 & 0 & 91.04 & 92.97 & 100 & 84.63 \\
\hline PRODUCTION LINE OEE \% & 88.01 & 87.46 & 98.24 & 75.2 \\
\hline
\end{tabular}


$75.2 \%$. From the cause and effect diagram it is found that Improving product quality is generally not difficult, but requires deliberate and ongoing attention, and it requires the commitment of every individual within the manufacturing company, from the person who cleans the floors to the most senior manager. Manufacturing the quality product is mandatory to sustain in this globally competitive market. Therefore, it is very important to see to it that garments are made of high quality. Poka-yoke, TPM \& OEE tools were applied to increase efficiency, reduce product error and workin-progress to achieve a high-quality product. It plays an important role in maintaining the quality of clothes. Minimizing defect is very important for ensuring the quality of products.

\section{References}

[1] George L. Hodge, Kelly Goforth Ross, "Adapting lean manufacturing principles to the textile industry," 2011.
[2] George L Hodge, Kelly Goforth Ross, Jeff A Joines, Kristin Thoney, "Adapting lean manufacturing principles to the textile industry," Production Planning \& Control, 22(3), 237-247, 2011.

[3] Laura C. Maia, Anabela C. Alves, Celina P. Leão, "Sustainable work environment with lean production in textile and clothing industry," International Journal of Industrial Engineering and Management, 4(3), 183-190, 2013.

[4] Kazım Hanbay, Muhammed Fatih Talu, Ömer Faruk Özgüven, "Fabric defect detection systems and methods-A systematic literature review," Optik, 127 (24), 11960-11973, 2016.

[5] G. Q Huang, P. K. Wright, Stephen T. Newman, "Wireless manufacturing: a literature review, recent developments, and case studies," International Journal of Computer Integrated Manufacturing, 22 (7), 579-594, 2009.

[6] Farhana Ferdousi, and Amir Ahmed, "An investigation of manufacturing performance improvement through lean production: A study on Bangladeshi garment firms," International Journal of Business and Management, 4(9), 106-116, 2009.

[7] Rasoul Shafaei, "An analytical approach to assessing the competitiveness in the textile industry," Journal of Fashion Marketing and Management: An International Journal, 2009. 